\title{
Mathematics Teachers' Early Lesson Study Experiences in Turkey: Challenges and Advantages
}

\author{
Mesut Bütün ${ }^{1, *}$ \\ ${ }^{1}$ Faculty of Education, Sivas Cumhuriyet University, Sivas, Turkey \\ *Correspondence: Department of Mathematics and Science Education, Faculty of Education, Sivas Cumhuriyet \\ University, Sivas, Turkey. E-mail: butunmath@gmail.com
}

Received: August 17, 2019

Accepted: September 26, 2019

Online Published: October 17, 2019

doi:10.5430/wje.v9n5p51

URL: https://doi.org/10.5430/wje.v9n5p51

\begin{abstract}
The purpose of this study was to reveal the challenges and advantages of the implementation of the lesson study model in Turkish middle schools. This study was a case study and the participants of the study was 11 middle school mathematics teachers in three different school in a city at central Anatolia region of Turkey. Three lesson study cycles were carried out at one month. The data were collected with field notes, focus group interviews and an open-ended questionnaire. Data were analysed by using content analysis. Moreover, direct quotations from teachers' views were also included. Findings indicated that teachers had prejudice that the lesson study implementations would not help their professional development. However, their prejudices were positively changed and they began to show interest when they attended the implementations of lesson study. Implementation of the lesson study model enabled the teachers to share experiences, to focus on students' thinking / understanding, it also enabled teachers to be more active, to examine the curriculum and resources related to instructional materials in depth. On the other hand, challenges in the process of lesson study implementation were as follows: time problem, teachers' ego and fear of being observed, adaptation of students in research lessons, differences between researcher and teachers' views about mathematics teaching, the intensity of the curriculum and the pressure of the central exam.
\end{abstract}

Keywords: lesson study, mathematics teacher, challenges, advantages, teacher education

\section{Introduction}

Lesson study is a professional development model which includes the stages of planning, conducting and evaluating effective lessons that will enable the student to learn in with the collaboration of teachers that originated in Japan (Fernandez \& Yoshida, 2004, Stigler \& Hiebert, 1999). In this model, teachers find solutions with working cooperation to problems which they encounter in their classroom, test their solutions, evaluate the results and share them with other colleagues. Lesson study is a teacher-led professional development model with a long history in Japan, which has spread rapidly to other countries in recent years (Lewis \& Lee, 2016). Murata (2011) lists main characteristics underlying this rapid spread and remarkable success of the lesson study. These characteristics include the centralization of teachers' interests and needs, being student oriented, including research lessons that enable teachers to become researchers, and also being a reflective and collaborative process. Since teaching is a cultural activity (Stigler \& Hiebert, 1999), the adaptation of the lesson study to different countries and cultures and the determination of the compatible and incompatible points of those countries with the education system has become the point of many studies (Khokhotva, 2018; Lewis, Perry, \& Murata, 2006; Ni Shuilleabhain, 2018, da Ponte et al., 2018 ).

For example, in the United States, the lesson study model has attracted the attention of American educators with the work of Stigler and Hibert (1999), followed by practice in many schools both on a provincial and national level (Murata, 2011; Yoshida, 2012). Although it has been stated in many research reports that the applications have a positive effect on the development of the qualifications of mathematics teachers, it has been found out that there are some cultural difficulties especially in the first applications (Takahashi \& Yoshida, 2004; Lewis, 2011, Xu ve Pedder, 2015). The fact that teachers generally carry out their professional work individually and are not accustomed to working in collaboration, cannot find time and financial resources to carry out detailed studies required by the lesson 
study model, not receiving sufficient support from the school administrations and local education authorities, in addition, the concerns of observation by colleagues in their classrooms and their willingness to see the results of their practices in a short time are listed as the main factors that make it difficult to implement the lesson study (Sjostrom \& Olson, 2011). In the UK, the implementation of the lesson study model has become widespread through the work of Dudley $(2012,2013)$, a recent national project. Dudley (2014) found that lesson study activities help teachers to reveal tacit knowledge structures and facilitate the learning of teachers from each other with different professional experiences. Moreover, Dudley (2014) states that lesson study creates a safe learning environment by enabling teachers to take risks together associated with their teaching practices. Studies conducted in Ireland and Portugal have revealed that lesson study help mathematics teachers perform teaching in line with the recommendations in their innovative curriculum (Ni Shuilleabhain, 2018; da Ponte, Quaresma, Mata-Pereira, \& Baptista, 2018). During the planning phase in lesson study activities, it is stated that as a result of anticipating student thoughts and comparing these predictions with real situations in research lessons, teachers have realized a profound change from traditional, "transmissive" approach to teaching to "inquiry-based teaching" methods (Clivaz \& Takahashi, 2018). On the other hand, in these studies, it was found out that teachers had problems finding time due to their workloads and difficulties were encountered in ensuring the sustainability of lesson study applications. In Indonesia, the implementation of the lesson study model has been carried out since 2006 by spreading across the country (Hendayana, 2015). It is stated that professional knowledge and skills of the teachers were developed by participating in the practices, collaborative studies, observing colleagues and by doing self-evaluations through video sections of the lesson study model they design. These examples of practices in different countries on the effectiveness of the lesson study model can be further reproduced. However, the main point that needs to be taken into consideration here is that in any country or culture, some common difficulties are encountered especially in the early stages.

Xu and Pedder (2015), examining 67 scientific studies carried out in 18 different countries related to the lesson study model, listed the general difficulties as follows:

1) Time problem of teachers to carry out intensive studies required by the lesson study model,

2) Implementation of the model creates extra workload for teachers,

3) Inadequate provision of school administrators and local education authorities to ensure the sustainability of lesson study-based practices,

4) The culture of working in cooperation among teachers is not established,

5) Implementations require cost.

Compared with studies abroad, studies related to lesson study model in teacher education in Turkey is quite new. In these researches, mostly pre-service teachers were studied within the scope of Teaching Practice Course and focused on the development of the pre-service teachers in the process (Baki, 2012; Baki \& Arslan, 2012; Bütün, 2015; Güner \& Akyüz, 2017). The in-service training focused on the development of teacher knowledge and skills rather than revealing the difficulties experienced during the implementation of the lesson study model (Boran \& Tarım, 2018; Çelik \& Güzel, 2017; Kaya, 2018). However, before a new model from different cultures becomes widespread in a culture, the challenges and advantages of the implementation of the model need to be identified. If this could be done, both there would be a ground for future implementations and there also would be an opportunity to compare the results of international studies with those outlined above.

In this context, the lesson study model was implemented with mathematics teachers in a middle school. Therefore, the aim of the study is to reveal the challenges and advantages during the implementation of the lesson study model.

\section{Method}

The research methodology of this study was case study. Multiple data collection tools were included in the case studies for an in-depth investigation to find out how specific theories or models work in different contexts (Leymun, Odabaş1, \& Yurdakul, 2017). The aim of this study was to reveal the experiences, challenges and advantages of lesson study model which was implemented for the first time in three middle schools. In this process, teachers' views and the field notes of the researcher were taken into consideration.

\subsection{Participants}

The participants of this study was 11 middle school mathematics teachers in Turkey. They implemented lesson study model in 3 different schools. These schools were in a city at central Anatolia region of Turkey. In the study, lesson 
study groups were formed with mathematics teachers in each school. Information about the teachers and schools were presented in Table 1:

Table 1. Demographical Characteristics of Schools and Teachers

\begin{tabular}{llll}
\hline School $^{*}$ & Teachers & Years in service & Gender \\
\hline $\mathrm{M}$ & $\mathrm{T} 1$ & 10 & Male \\
& $\mathrm{T} 2$ & 17 & Male \\
& $\mathrm{T} 3$ & 29 & Female \\
& $\mathrm{T} 4$ & 16 & Female \\
$\mathrm{B}$ & $\mathrm{T} 5$ & 2 & Female \\
& $\mathrm{T} 1$ & 13 & Male \\
& $\mathrm{T} 2$ & 14 & Female \\
$K$ & $\mathrm{~T} 3$ & 35 & Male \\
& $T 1$ & 13 & Male \\
& $T 2$ & 13 & Male \\
\hline
\end{tabular}

* The first letter of the name of the schools were coded as M, B and $\mathrm{K}$

\subsection{Process}

The lesson study cycles were implemented at one month. In the first step, the researcher gave information to the teachers about the stages of the lesson study model. Moreover, he shared sample videos and research results from literature at the meeting lasting four hours. In the second step, teachers identified a problem/ focus point guided by the researcher. Then they prepared lesson plans for research lessons. At this stage, a lesson plan template was presented for teachers in order to prepare lesson plans. In this template, teachers were asked to indicate their own actions and anticipations about student understanding in different time periods. In the third step, the lesson plans were implemented in real classes in three different schools. The researcher was included in the research lessons together with the teachers and kept field notes in the classroom. In the last step the plan was evaluated and, post-lesson discussion was carried out. At this final step, observations in the research lessons were shared and it was argued whether the learning outcomes related to the students learning were reached or not. The author of this study was knowledgeable other in planning and post-lesson sessions except for other steps of the lesson study cycle. Table 2 shows the activities and content of the research process:

Table 2. Activities and Content of Process

\begin{tabular}{|c|c|c|}
\hline Week & Activities & Content \\
\hline 1 & Introduction of lesson study & $\begin{array}{l}\text { Give information about } \\
\text { the stages of the lesson study model } \\
\text { Sample videos and research results from literature } \\
\text { Temple of lesson plans and observation forms }\end{array}$ \\
\hline 2 & Preparation of lesson plans & $\begin{array}{l}\text { Focusing teaching problems, formulating goals for student } \\
\text { learning and planning research lessons }\end{array}$ \\
\hline 3 & $\begin{array}{l}\text { Research lessons and post-lesson } \\
\text { debriefing sessions }\end{array}$ & $\begin{array}{l}\text { Implementing the lesson plans in research lessons and } \\
\text { debriefing the research lessons }\end{array}$ \\
\hline 4 & $\begin{array}{l}\text { General evaluation of lesson study } \\
\text { cycles }\end{array}$ & $\begin{array}{l}\text { Evaluating the lesson study cycles } \\
\text { Filling the open-ended questionnaire } \\
\text { Making focus-group interviews }\end{array}$ \\
\hline
\end{tabular}

\subsection{Data Collections}

The data were collected with field notes, focus group interviews and an open-ended questionnaire. The field notes were kept in order to describe the experiences in each phase of the lesson study cycle. In addition, at the end of the study, the teachers' views about the lesson study cycles, an open-ended questionnaire and focus group interviews were used. The questionnaire had seven open-ended questions. In this questionnaire, teachers were asked to express their views about the contribution of the lesson study to their professional development, to give suggestions for more effective usage of the stages of lesson study and to share views on the implementations of the lesson study model in 
the current education system. About 40 minutes after this stage, the focus-group interview was conducted. In this interview teachers were asked to elaborate their responses to the questionnaire. All stages except research lessons were recorded with video. There was no video recording in order to prevent deterioration of the natural environment during public research lessons.

\subsection{Analysis of the Data}

Data were analysed by using content analysis. Data analysis took place in two stages. In the first stage, all audio recordings obtained during the research process were written and the documents (written statements in open-ended questionnaire form, observation field notes) were transferred to the computer environment. In the second stage, data were classified by focusing on the challenges and advantages on the implementation of the lesson study. This classification was made by using constant comparison method by coding, categorizing and reaching themes (Strauss \& Corbin, 1990). The researcher's field notes were determined for each theme that emerged in the process and in the presentation of the findings, these sections were transferred as supporting / contradictory data. In addition, these field notes were used to reflect and describe the experiences in a context where the lesson study model was applied for the first time from the perspective of the researcher. In the presentation of the findings, the emerging themes were supported by direct quotations from the teachers' expressions. The teachers, the schools and experience of teachers were coded given in Table 1. For example, T2 represented teacher, 14 represented experience and B represented school in the T2B14.

\section{Findings}

The findings were presented as following sub-titles; beginning of the process (Lesson study introductory meeting), advantages and challenges.

\subsection{Beginning of the Process (Lesson Study Introductory Meeting)}

Discussions were initiated by asking teachers to comment on in-service training activities they had attended until that time. In general, it has been stated that teachers are not satisfied with current in-service training practices. Here are two excerpts from that point of views:

I worked for years as a manager and teacher. In these seminars only the slide is read, the theoretical information is being conveyed. The useful seminars we have taken so far are too small to be counted in fingers (T3B35).

I have been teaching for 29 years. I also attended many seminars. Trainers read the slayts therefore we do not want to listen to them. We are not taught what we expect from students during these trainings. We do not talk about these (issues). I think so about this training (referring to the lesson study) (T3M29).

Even though the teachers voluntarily participated in the study, they retained the expectation of the lesson study according to their previous professional learning experience (which is also useless). The above statements indicate that the previous in-service training experience of the teachers did not satisfy them. Teachers stated that they are not only listeners in the in-service training activities, but also have a desire to create learning environments in which they will play an active role.

In the following stage a video of a research lesson in Japan was presented (10 minutes section) before the teachers were presented with information on lesson study model. The researcher took attention to the people who were taking notes about the students' learning in the monitored video and the teachers were asked what they watched on the video, who they were, what they did, and general evaluations were taken. Teachers stated that people in the video may be academicians, pre-service teachers, pedagogues or people from the profession. The researcher said that the class in this video was a mathematics class in Japan after talking about the relaxed behaviour of the children by resembling the class in the monitored video to a laboratory where teachers were doing research. Afterwards, the lesson study model and the steps in this model were introduced and short sections of the results of the international studies were presented. Then, teachers were given the opportunity to talk about their first impression of the lesson study model. Here is a section of the teachers' mutual talks:

... at least 5th grade. The perception of a student at the 5th grade is approximately the same. The samples we have, the level is caught. Small differences can be made according to grades ...if there is a good dialogue between the teachers in the school you work in, everyone is open to self-renewal, if people do not criticize each other about what they do not know this model can be used (T3M29).

...i saw the goal as this. We actually learn mathematics teaching by doing. In fact, this is what we learn by 
doing, learning mathematics teaching (T4M16).

There can be a beauty in this system. For example, a Turkish Proverb says "Two heads are better than one", a friend can come up with a different idea, the point of view is very different. It could be such a positive side (T1K13).

The above discussions reflect the fact that teachers' expectations have increased after the presentation of the lesson study model and they have developed positive thinking before the process related to the model.

Subsequently, teachers from three schools prepared a lesson plan under the guidance of the researcher (provided with lesson plan template and guidelines to the teachers) in the context of a topic/learning attainment that they identified in groups. In determining the attainments, teachers focused on mathematical concepts that students had difficulties or misconceptions more. Lesson plans were prepared according to these attainments; "Finds the area of the square and rectangle, solves the related problems (in grade 5)", "in performs the subtraction in the integers (in grade 6)", "calculates the length of the circle and the circle part (in grade 7)".

In the first stage, the group of teachers in each school prepared a plan among themselves, and then these plans were made available to all teachers in the environment. And these plans were debated in different ways. Subsequently, research lessons were implemented in these three schools and a final debriefing session was held. The advantages of the process and the difficulties encountered are covered under the following headings.

\subsection{Advantages}

Implementation of the lesson study model enabled the teachers to share experiences, to focus on students' thinking / understanding, it also enabled teachers to be more active, to examine the curriculum and resources related to the course in depth. These advantages are listed below.

\subsubsection{Share Experiences}

Teachers have had the opportunity to share problems about mathematics teaching with their colleagues experienced individually in their classes during the lesson study. Thus, teachers were able to compare their mathematics teaching experiences with their colleagues and developed a critical point of view to their practices. In the open-ended questions at the end of the process, some of the sections expressed in this direction are presented below.

The exchange of experience among the colleagues was quite useful from my point of view. I also had the opportunity to criticize myself (T2B14).

"I think the strongest aspect of the lesson study is that, teacher prepare a lesson plan and share ideas with his colleagues (T3K13).

"Learning teaching methods from different teachers, seeing the methods of implementation ... was invaluable (T3M29).

The above opinions show that this first lesson study experience of teachers creates a unique context for sharing their professional knowledge and skills. Some of the ideas expressed in the focus group discussion at the end of the session supported this finding. T5M2, a 2-year teacher, stated that he encountered difficulties while teaching mathematics in the first year of his career, but he did not have the opportunity to share these problems with other teachers. Also, T3B35 stated that during the meetings at the beginning and end of the semesters, based on exam data teachers have jointly determined the subjects that students have learning difficulties. However, they stated that they planned the decisions / actions related to teaching separately. The field notes at the evaluation meeting revealed that the other teachers also supported these opinions, and that they agreed with the idea that the traditional teacher meetings were not effective enough to share experiences. All these findings obtained in the lesson study process showed that the experience of teachers in joint decision-making and sharing responsibilities related to teaching helped to create a professional learning community.

\subsubsection{Focus on Student Thinking/Understanding}

Lesson study cycles have been a convenient context for teachers to develop their understanding about the mathematical misconceptions of the students. Especially in the sessions of preparation of the lesson plan, studying about the anticipation of students' thinking and identifying teacher actions that might correspond to them (with the guidance of the researcher) has become a rich learning environment for the teachers. The field notes held in these meetings revealed that more experienced teachers based on their own past experiences in determining the anticipation of students' understanding, and the inexperienced teachers mostly directed to external sources (books, articles, reports, etc.). As a result of their application of external sources, they faced different student misconceptions 
and developed solutions to these problems. Here are some teachers' opinions on focusing on student thinking:

It was a good work. At this stage, we tried to make the students understand the difficulties that we anticipated (T1M10).

It is very useful to exchange opinions on misconceptions and difficult topics (T2K13).

We can say that the possible difficulties of the students, determining the points that they can fall into the mistakes, and taking precautions to these mistakes will be a good teaching system component (T3B35).

The observations made in the research lessons reveal that the focus of the observers is on the things those students rather than the teachers. The fact that the focus was in this direction also helped the teacher who worked in the lesson to move more easily and thus not to disturb the naturalness of the classroom environment. At the end of the study, 2 teachers stated that students in different levels (low-medium-high) are defined and it would be more appropriate to focus on these students in observations. In the focus group interview, teachers were asked why they thought this way. Teachers stated that they put forward this proposal in order to make the evaluation meetings at the end of the research lessons more functional and to facilitate the follow-up of the progress of the students during the lesson study process. Lesson study has been evaluated as "a unique approach (T1K13)" in order to follow and support especially low-achieving students.

\subsubsection{Activating Teachers}

The lesson study work has positioned teachers as key factors in practices, unlike their previous in-service experiences. Teachers, who were in the foreground from the determination of topics in the research lessons to the design of the lesson, were thus more attached to the study. Teachers' views on this issue are presented below:

It is certain that there is a difference. At the very least, the teacher is not the listener, but the practitioner (T3B35).

It is an application that teachers and students apply together. It is obvious that it kept me alive throughout the process because it is not only based on theoretical knowledge (T2B14).

... absolutely different. It is an applied study in which teacher is actively involved. All told and explained are practiced (T2K13).

These statements showed that during the lesson study, teachers are transitioning from listeners to practitioner roles and become more active by bridging theory and practice. Teachers' ability to observe their projections and predictions in their planning sessions in their research lessons has increased their self-confidence and courage by making it easier for them to take common risks. The field notes held during the sessions show that the teachers who were left behind in expressing their ideas and sharing were more active as the process progressed.

\subsubsection{Examination of Curriculum and Resources}

The lesson study works, especially during the planning phase, has provided teachers with an opportunity to examine the curriculum forward and backward. Those works have also directed teachers to identify appropriate instructional materials and to search for resources to investigate student thinking / misconceptions. In this process, the researcher tried to facilitate the process by suggesting various sources. In the meetings, teachers were given the opportunity to access internet to read the articles about the mathematics teaching method and the students' misconceptions. Thus, teachers had the opportunity to compare and evaluate their own foresights/ anticipations about student understanding and the results presented in academic studies. However, observations in the meeting environment revealed that most of the teachers' knowledge of the curriculum was superficial (for example, knowing in which grade the related concepts were discussed for the first time in the past). Teachers need to be aware of these shortcomings in the process of preparing a plan and need to examine the program in detail. Sections from the teachers' views on this point are presented below:

I think it's a general problem that teachers do not have an adequate knowledge on curriculum. With this work we had the opportunity to review both again and together (T13K13).

I personally did not know that there were so many resources related to the issue (about student misconceptions). What ores are in friends! (T3M29).

As reflected in the statement of $\mathrm{T} 3$ above, most of the teachers in the study (especially experienced teachers) have been aware of the existence of academic studies on students' misconceptions during the lesson study process. At the end of the study, a few of the teachers stated that the reports to be generated from the lesson study work could be used in the revision of curriculum. The teachers, who complained that the changes in the curriculum do not generally 
apply to their opinions, stated that if the lesson study studies become widespread throughout the country, there will be a great potential in this sense.

\subsection{Challenges}

\subsubsection{Time Problem}

Naturally, a special time slot was required for conducting the lesson study sessions (except from class hours). This lesson study research was realized during a period when the workload of the teachers was relatively light during the spring term. Of course the procedural arrangements of The Provincial Directorate of National Education (permits etc.) and school administrators' positive view have facilitated the process. However, when the field notes in the research process and teachers' opinions on future practices are examined, the time factor has emerged as a fundamental problem. Two sections from the views of teachers participating in the study (almost all teachers share the same view) are presented below:

\section{It is hard for all teachers to be available for planning and implementation (T3M29).}

Time for the meetings in preparation phase. I think that's the biggest problem (T2K13).

In Turkey teachers have to stay at school even if they don't have course hours but generally they don't stay at school apart from course hours. In this context, teachers may have considered the time and studies required for the lesson study as an extra workload. It can be said that this difficulty has been exceeded for teachers to a certain extent in this study with the excitement of trying a new method and attending voluntarily. In the focus group interview conducted at the last evaluation meeting, the teachers were asked what suggestions they had to overcome the time problem in order to facilitate the future study of the lesson study. Some of the teachers stated that they should be given the tuition fee for these studies which require extra time during the semester, while the other part stated that they could plan and evaluate the lesson studies during seminars which are at the beginning and end of the academic year (15 days).

\subsubsection{Teachers' Ego and Fear of Being Observed}

It has been observed that in the working environment, teachers sometimes show attitudes such as underestimating the contribution of others by emphasizing their own views. This has led some teachers to stay on the back and have felt anxiety while explaining their views. When such situations were observed in the sessions, the researcher encouraged the teachers who were left behind and encouraged them to express their opinions. For similar reasons, it has also been revealed that teachers can also experience observation anxiety in their research lessons. Here are some teachers' opinions on this issue:

\section{Teacher's ego is in front of the lesson study (T1K13).}

The inter-teacher dialogue should be good. No one will want to do so long as there are teachers who are looking for the deficiencies of one another (T2K13).

The teacher will think that he/she is at the center of criticism (T3M29).

The first two quotes presented above are the discourse of two teachers who work in the same school. Observations in the meeting environment reflected a tension, contention between teachers before the session in this group. During the course of preparation of the lesson plan, the researcher provided this group with academic guidance, on the other hand, he faced the difficulty of reducing the tension. Observations in research lessons also showed that fear of individual deficiencies, teachers may feel anxiety of observation. Teachers' hectic attitudes came to the fore especially in situations that were not foreseen in the lesson plan but were spontaneously developing in the classroom (for example, when an unexpected student question came up). Even though the focus is on learning in the research classes rather than on teacher actions, it can be seen as another reason for teachers' anxious attitudes when they teach for the first time in front of their colleagues.

\subsubsection{Adaptation of Students in Research Lessons}

Contextual difficulties in research lessons have also made the practise difficult to apply. It was disturbing that more than one teacher entered the classroom together and students were in focus of observations that they were not accustomed to. Occasionally, teachers' walked up and down in the classroom and took notes about what students were doing caused students to be distracted. Here are some excerpts reflecting teachers' views on this direction:

The environment in which students can feel comfortable about this situation must be ensured. If students can feel comfortable, we get more efficiency (T5M2).

... but I have observed that some students are worried about different teachers, and that they are not actively 
involved. I think student will get used to this as time passes (T4M16).

In this study, no camera was used in observations in research lessons in order not to disturb the natural environment of the class and distract students. Teachers and researchers recorded observation notes in a column opened in the form of a lesson plan. In these classes, where the class sizes are between 25-35 and the students are usually working individually, it was difficult to determine which students to focus on observations. In a limited time frame, teachers had to identify students who would gather evidence for their individual learning as well as to take notes about the overall class. The researcher's field notes revealed that teachers' lack of knowledge and skills of formal observation were also effective in the emergence of this difficulty.

\subsubsection{Differences between Researcher and Teachers' Views about Mathematics Teaching}

It has become clear that, in the stage of planning the research lessons in particular, there may be profound differences between the teachers' proposals and the researcher's thinking. These differences sometimes make it difficult to plan while bringing rich arguments. For example, in the lesson plan designed to teach addition and subtraction in integers, in one of the lesson study groups the teachers gave a rule-based explanations emphasis (i.e. the sign of the second number is changed, and then the rule operation of addition is applied). The researcher in the facilitator role has suggested approaches such as modelling with counters, but has not been adopted by teachers. It was seen as sufficient for the students to find out the result of the operation by applying the correct rule. The research lesson in the direction of the plan was a course focused on procedural learning rather than conceptual learning. When the data were being discussed at the post-lesson evaluation meeting, a teacher said "the rules we give are already forgotten" and then the researcher stated that the continuity can be increased in the case that the operations are taught in the integers as suggested before the lesson. The observations of the researcher in the post-lesson meeting environment revealed that teachers could prefer rule-based instruction in research lessons due to their lack of pedagogical content knowledge. This inadequacy was reflected in the evaluation meeting that the researcher conducted by modelling the processes discussed in the course, and the questions posed by the teachers and the controversies between them.

Teachers in the other two groups were more compatible with the researcher in the plan preparation stage and turned their differences into an advantage by including different elements in their plans. For example, in the lesson plan, the task was formed to support both conceptual and procedural knowledge. On the other hand, the researcher in the role of facilitator has difficulty in how and when to intervene in the discussions and designs of the teachers in some cases. On the one hand, he made efforts to not direct the teachers more than necessary according to his point of view and not to adopt an authoritarian position. On the other hand, in order to prepare a systematic and progressive lesson plan, he had to explain the teaching decisions on questions from the teachers. This difficulty in preparing the lesson plan was less experienced at the post-lesson evaluation meetings. Because, in these meetings, the teaching approaches for the future courses were determined by providing a full consensus based on the concrete data obtained from the research lessons.

\subsubsection{The Intensity of the Curriculum and the Pressure of the Central Exam}

Teachers stated that it was an intensive curriculum that needed "finish" until the end of the term, which would make lesson study works harder. They also stated that they felt under pressure because of the central exam at the end of the middle school, and they were seen as first responsible for accountability. They argued that this would affect their loyalty and sustainability for lesson study works. Below are the two sections of this direction from the teacher discourse at the end of the study.

Here is a gradual development (the development of the pupils) by means of the lesson study. But there is an examination in the short term and we are the first responsible for failure. Exam-focused teaching will make it difficult to implement this model (T2K13).

The curriculum is intensive, there are a lot of topics, we have to finish at the end of the semester. I think the curriculum needs to be simplified so that it can be applied effectively (T2M17).

The expression of the first teacher above reflects the fact that lesson study is not a model that changes student success from today to tomorrow. The second teacher stated that the number of subjects in the curriculum is too much and they should be simplified. These views point out the difficulties that may occur in future implementations according to the teachers. Teachers stated that unless they shared the common responsibility in the lesson study by other stakeholders in education, the model would not have sustainability and the pressure on them would increase. In the last evaluation meeting of the lesson study, the issue of why subject density reduction is necessary is discussed. In this meeting, it was stated that the change / amendment of the curricula would be a more reasonable way to be carried out in the light of the lesson study evaluation reports not in a way top to down. 


\section{Discussion and Conclusion}

In this study, a lesson study model was put into practice with the participation of mathematics teachers from three different middle schools. Teachers, who were introduced to this model for the first time through this study, conducted the lesson study cycles under the guidance of the author of the research and revealed the advantages and challenges of the model depending on the experiences in the process. In the following section, these aspects of lesson study were discussed and compared with the results obtained from international practices and implications of the findings are discussed for future studies in the context of Turkey.

The first stage of the study is a lesson study presentation meeting. In these meeting, with the effect of the previous experiences of teachers in in-service training programs, the prejudices about the failure of this approach were noticed. In new cultural contexts, it is stated that that there may be some perception such as here today gone tomorrow. (Cajkler, Wood, Norton, \& Pedder; 2014; Murata, 2011). After the introduction of the lesson study model to the teachers, it was found out that teachers' expectations about this in-service training activity increased and they developed positive thoughts. It can be said that these positive thoughts have evolved since the work of lesson study has a collaborative nature, it is different from the previous in-service activities and as also reflected by the expression of a teacher "learn mathematics teaching by doing" means lesson study activities will give them the opportunity to learn by doing.

Lesson study model helped mathematics teachers to share experiences, to bring out their individual applications and tacit knowledge in their classrooms. Dudley (2013) states that teacher talk in lesson study cycles can allow teachers to access each other's tacit professional knowledge stores. The problems of the teachers about the students' learning of mathematical concepts have been revealed and the problems they experienced in their classes have turned into common problems of the group. As a result, teachers have increased their commitment to work by ensuring that they take common risk and responsibility. Dudley (2104) states that teachers take common risks with others and this creates a safe environment for them to develop themselves in areas where they feel inadequate.

Teachers' focus on student thinking / misconceptions and benefiting from each other's experiences during the lesson study also helped teachers improve their knowledge of students understanding. Teachers face different student misconceptions and make suggestions for solutions other than their own anticipations and predictions by applying to research articles and academic sources and all these can be considered as indicators of this development. There are many studies in the literature states that lesson study has made a significant contribution to teachers' knowledge of student thinking / understanding. (Fernandez, 2005; Lee, 2008; Yoshida \& Jackson, 2011).

Unlike their previous in-service experience, teachers pondered on the teaching problems they had identified in the lesson study process, produced solutions to these problems, implemented these solutions in real classes and evaluated their results. This progressive active learning process has both positively affected the sustainability of the study and increased the self-confidence of teachers regarding their competencies. Teachers who were left behind during the initial phase in the groups became more active as the result of this process progressed. Also, during the preparation of the lesson plans, the curriculum was examined in detail in a forward and backward way so that teachers had the opportunity to deepen their knowledge about the program. After lesson study, teachers realized that they could contribute to the revision of the curriculum in case of sharing their studies and reports with other partners. As revealed in this study, in Turkey teachers' views are not taken into account, also they were considered as the only implementer of curriculum and teachers complain about this situation (Kaya, 2018). In this context, the dissemination of the lesson study will facilitate the development of the curriculum by providing data on both the implemented curriculum and it will be a tool for changing the traditional roles of teachers.

In this study, some difficulties have been observed and reported during the implementation of the lesson study model in different countries. For example, the problem of the need for extra time for lesson study (Norwich \& Ylonen, 2013; Sjostrom \& Olson, 2011; Xu \& Pedder, 2015) was one of the most common difficulties. In fact, time problem, which is often expressed, is a systemic and cultural one at its core. It is a problem for a teacher to participate approximately 30 hours per week required by lesson study model with his / her colleagues except from the normal class hours. It is also influential in the perception of the teacher's work as "entering and leaving the classroom" and this is perceived in culture in this way. It would be optimistic to expect these culturally embedded perceptions and practices to change spontaneously in a short time. Lesson study activities can be used easier with the help of official authorities since they can make arrangements about the system and also adopt this model.

The lack of collaborative work culture among teachers has reduced the effectiveness of group work, as it has been in this study (teachers' egos, obsession, fear of auditing). Teachers need to face their weaknesses as well as their strengths (Xu \& Pedder, 2015). The difficulties mentioned can be overcome by making longer practices (until the 
perception that the focus is not on the behaviour of the teacher but on the learning / understanding of the student occurs) and by emphasizing the positive results of these implementations especially on the students. Again, the case that students in the research lessons do not feel comfortable, which emerged in this study, will change with the progressive lesson study practices.

In this study, especially in the planning phase, there have been cases where profound differences between the perspectives of teachers and the researcher have arisen from the point of view of mathematics teaching. In such cases, the researcher did not take an approach such as imposing his own point of view or proposing an implementation in order not to disrupt the nature of the lesson study. But this time, the teachers have adopted a rule-based teaching style in the research lesson. Of course, it is difficult to change teachers' ongoing traditional mathematics teaching practices in a sudden. With lesson study, it is stated that teaching process is shifted from teacher-centered teaching to student-centered teaching (Clivaz \& Takahashi, 2018; Fernandez, 2005; Stigler \& Hiebert, 1999). This change is facilitated because the nature of the lesson study inherently requires teachers to develop lesson plans that focus on student understanding. In this process, teachers naturally question and change their perspectives and ongoing traditional mathematics teaching practices by collaborating, discussing, researching, and receiving feedback from real classes. Longer lesson study implementations are required for this purpose.

The lesson study model can be disseminated and teachers' plans/reports can be accessed by stakeholders, curriculum can be simplified, which makes implementation difficult. To ensure the expansion of the model, lesson study websites can be established in Turkey. Through these websites, certain parts of the lesson study (such as goal setting, planning and sharing results) can be realized on the web. Thus, a contribution will be made for the solution of the above-mentioned time problem. It is also possible to reduce the pressure on teachers and increase the sharing of responsibility by involving education policy makers, school administrators and even student parents in the lesson study process.

\section{References}

Baki, M. (2012). Investigating development of prospective primary teachers' mathematical pedagogical content knowledge: Lesson study. (Unpublished Doctoral Dissertation). Karadeniz Technical University, Trabzon, Turkey.

Baki, M., \& Arslan, S. (2012). Investigating Prospective Primary Teachers' Knowledge in Teaching through Lesson Study. In 12th International Congress on Mathematical Education, COEX, Seoul, Korea.

Boran, E., \& Tarım, K. (2018). Ortaokul matematik öğretmenlerinin ders araştırması modeli ile özel alan yeterliklerinin öğretime yansıması. International Journal of Educational Studies in Mathematics, 5(1), 23-38.

Bütün, M. (2015). Öğretmenlik uygulaması dersinde ders imecesi modelinin değerlendirilmesi: Sorunlar ve çözüm önerileri. Adlyaman Üniversitesi Eğitim Bilimleri Dergisi, $5(2), \quad$ 136-167. https://doi.org/10.17984/adyuebd.07565

Cajkler, W., Wood, P., Norton, J., \& Pedder, D. (2014). Lesson study as a vehicle for collaborative teacher learning in a secondary school. Professional Development in Education, 40(4), 511-529. https://doi.org/10.1080/19415257.2013.866975

Çelik, Ö. A., \& Güzel, B. E. (2016). Bir matematik öğretmenin ders imecesi boyunca öğrencilerin düşüncelerini ortaya çıkaracak soru sorma yaklaşımları. Turkish Journal of Computer and Mathematics Education, 7(2), 365-392. http://doi.org/10.16949/turcomat.67541

Da Ponte, J. P., Quaresma, M., Mata-Pereira, J., \& Baptista, M. (2018). Fitting lesson study to the Portuguese context. In Mathematics Lesson Study Around the World (pp. 87-103). Springer, Cham. https://doi.org/10.1007/978-3-319-75696-7_5

Dudley, P. (2012). Lesson Study development in England: from school networks to national policy. International Journal for Lesson and Learning Studies, 1(1), 85-100. https://doi.org/10.1108/20468251211179722

Dudley, P. (2013). Teacher learning in Lesson Study: What interaction-level discourse analysis revealed about how teachers utilised imagination, tacit knowledge of teaching and fresh evidence of pupils learning, to develop practice knowledge and so enhance their pupils' learning. Teaching and Teacher Education, 34, 107-121. https://doi.org/10.1016/j.tate.2013.04.006

Dudley, P. (2014). How Lesson Study works and why it creates excellent learning and teaching. In Lesson Study (pp. 1-28). Routledge. https://doi.org/10.4324/9780203795538-1 
Fernandez, C. (2005). Lesson study: A means for elementary teachers to develop the knowledge of mathematics needed for reform-minded teaching?. Mathematical Thinking and Learning, 7(4), 265-289. https://doi.org/10.1207/s15327833mt10704_1

Fernandez, C., \& Yoshida, M. (2004). Lesson study: A Japanese approach to improving mathematics teaching and learning. Mahwah: Lawrence Erlbaum Associates.

Güner, P., \& Akyüz, D. (2017). Ders İmecesi Mesleki Gelişim Modeli: Öğretmen Adaylarının Fark Etme Becerilerinin İncelenmesi. Ilkogretim Online, 16(2). https://doi.org/10.17051/ilkonline.2017.304709

Hendayana, S. (2015). Teacher learning through Lesson Study in Indonesia. In Realising learning: Teachers' professional development through lesson and learning study (pp. 62-77). Routledge.

Kaya, Ü. (2018). Evaluation of High School Mathematics Teachers' Professional Development Practices Based on Lesson Study Model. Unpublished master's thesis, Sivas Cumhuriyet University, Sivas, Turkey.

Khokhotva, O. (2018). Lesson Study in Kazakhstan: case study of benefits and barriers for teachers. International Journal for Lesson and Learning Studies, 7(4), 250-262. https://doi.org/10.1108/IJLLS-04-2018-0021

Lee, J. F. (2008). A Hong Kong case of lesson study-Benefits and concerns. Teaching and Teacher Education, 24(5), 1115-1124. https://doi.org/10.1016/j.tate.2007.10.007

Leymun, Ş. O., Odabaşı, F., \& Yurdakul, I. K. (2017). Eğitim ortamlarında durum çalışmasının önemi. Eğitimde Nitel Araştırmalar Dergisi, 5(3), 367-385. https://doi.org/10.14689/issn.2148- 2624.1.5c3s16m

Lewis, C. (2011). Response to Part IV: Seeing the Whole Iceberg-The Critical Role of Tasks, Inquiry Stance, and Teacher Learning in Lesson Study. In Lesson study research and practice in mathematics education (pp. 235-240). Springer, Dordrecht. https://doi.org/10.1007/978-90-481-9941-9_18

Lewis, C., \& Lee, C. (2017). The global spread of lesson study: Contextualization and adaptations. In International handbook of teacher quality and policy (pp. 185-203). Routledge. https://doi.org/10.4324/9781315710068-13

Lewis, C., Perry, R., \& Murata, A. (2006). How should research contribute to instructional improvement? The case of lesson study. Educational Researcher, 35(3), 3-14. https://doi.org/10.3102/0013189X035003003

Murata, A. (2011). Introduction: Conceptual overview of lesson study. In Lesson study research and practice in mathematics education (pp. 1-12). Springer, Dordrecht. https://doi.org/10.1007/978-90-481-9941-9_1

Norwich, B., \& Ylonen, A. (2013). Design based research to develop the teaching of pupils with moderate learning difficulties (MLD): Evaluating lesson study in terms of pupil, teacher and school outcomes. Teaching and Teacher Education, 34, 162-173. https://doi.org/10.1016/j.tate.2013.04.012

Shúilleabháin, A. N. (2018). Enacting curriculum reform through lesson study in the Irish post-primary mathematics classroom. In Mathematics Lesson Study Around the World (pp. 65-85). Springer, Cham. https://doi.org/10.1007/978-3-319-75696-7_4

Sjostrom, M. P., \& Olson, M. (2011). Preparing for lesson study: tools for success. In Lesson Study Research and Practice in Mathematics Education (pp. 269-277). Springer, Dordrecht. https://doi.org/10.1007/978-90-481-9941-9_21

Stigler, J. W., \& Hiebert, J. (1999). The teaching gap: Best ideas from the world's teachers for improving education in the classroom. New York: Summit Books.

Strauss, A., \& Corbin, J. M. (1990). Basics of qualitative research: Grounded theory procedures and techniques. Thousand Oaks, CA, US: Sage Publications, Inc.

Takahashi, A., \& Yoshida, M. (2004). Ideas for establishing Lesson-Study communities. Teaching Children Mathematics (May), 436-443.

Yoshida, M. (2012). Mathematics lesson study in the United States: Current status and ideas for conducting high quality and effective lesson study. International Journal for Lesson and Learning Studies, 1(2), 140-152. https://doi.org/10.1108/20468251211224181

Yoshida M., \& Jackson W. C. (2011). Response to Part V: Ideas for Developing Mathematical Pedagogical Content Knowledge Through Lesson Study. In: Hart L., Alston A., Murata A. (Eds.), Lesson Study Research and Practice in Mathematics Education. Springer, Dordrecht. https://doi.org/10.1007/978-90-481-9941-9_22

Xu, H., \& Pedder, D. (2014). Lesson Study: An international review of the research. In Lesson Study (pp. 29-58). 
Routledge. https://doi.org/10.4324/9780203795538-2

\section{Note}

A short version of this study was presented in The World Association of Lesson Studies International Conference (WALS2017) in Nagoya University, Japan, in 2017. 